\title{
REGRESANDO SIEMPRE A AMÉRICA LATINA
}

\author{
Always returning to Latin America
}

\author{
Antonio López Hidalgo \\ Universidad de Sevilla (España)
}

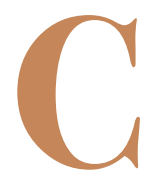

asi todos mis viajes a América Latina han estado motivados por razones académicas. El último me llevó a Perú y a Ecuador. Estuve una semana en Lima. Di algunas conferencias en las universidades de San Marcos y César Vallejo, bebí con los amigos, recorrí todo el centro colonial, el barrio de Miraflores y toda la costa hacia el sur en dirección al desierto de Chile, pero no alcanzamos a llegar. Ese mismo día, un terremoto de 7,8 en la escala de Richter, que duró casi setenta y cinco segundos, sacudió el norte de la costa ecuatoriana.

El epicentro del seísmo, ocurrido a las 18.58, hora local (01.58, hora peninsular española), de ese sábado 16 de abril de 2016, fue en el noroeste, entre las zonas de Cojimíes y Pedernales (Manabí) y se sintió en buena parte del país; en Quito, Guayaquil, Santo Domingo, Ibarra, Esmeraldas, entre otras ciudades. Los daños fueron graves en Portoviejo, Crucita, Pedernales, Tosagua, Manta, Muisne y afectó en menor medida a Babahoyo, Quito y Guayaquil. El terremoto se saldó con 671 personas muertas y más 2.000 heridos.

Las réplicas no dieron tregua en los días siguientes: 3.229 , de las que nueve superaron los seis grados. Al mes, una réplica de más de cuarenta segundos en Quito me hizo conocer en mi propia piel cómo se resquebrajaba la tierra en sus propias vísceras. Al día siguiente viajaba a Latacunga. A media mañana, una nueva réplica sacudió la ciudad. Me pilló en una pa- nadería que se balanceaba como si fuera un velero. El dueño, señalándome con la mano, me pidió que sujetara a una anciana, pero ella parecía más diestra en estos menesteres que yo. Se ve que la experiencia enseña más de lo que pensamos. El domingo 17 de abril, al amanecer y encender el móvil, múltiples mails de mis amigos preguntaban por mi salud. Me imaginaban en Ecuador y no en Perú. Les tranquilicé y bajé a degustar un pisco sour.

En Quito, desde la ventana del apartamento donde me hospedaba, observaba cada mañana la presencia imponente del Pichincha, el volcán más próximo a la ciudad. Me inquietaban su paz exterior y su corazón convulso. Tiene dos cimas principales. La más próxima, inactiva, el Rucu Pichincha (4.680 metros), es la menos elevada. La otra, el Guagua Pichincha (4.794 metros), la vigilan los vulcanólogos con una dedicación extrema. Quito, la segunda capital más elevada del mundo, está ubicada a una altura de 2.850 metros. El mal de altura provoca dolores de cabeza y mareos. Para minimizar estos malestares, conviene olvidar el tabaco y el alcohol. Un mate de coca alivia en estos trances.

En ese viaje a Latacunga, al día siguiente de la réplica que relato, subí para explorar más de cerca el Cotopaxi. Es uno de los volcanes más bellos de este planeta. Sus laderas heladas están pobladas de caballos salvajes, zorros, ciervos y osos de anteojos. Y alzando la vista se puede observar cómo cruzan el cielo el cóndor y el colibrí del Chimborazo. A fina- 
les de mayo del año anterior, 2015, con motivo de otra estancia académica, visité por primera vez Latacunga para dar un taller de periodismo narrativo en la Universidad Técnica de Cotopaxi. Ese verano el coloso comenzó a dar muestras de que estaba vivo. Unas 320.000 personas se vieron afectadas por la actividad fumarólica del Cotopaxi. Los campesinos observaron estupefactos los campos cubiertos con un manto gris de ceniza. Cenizas y flujos piroclásticos dañan las cosechas y asfixian a los animales.

Unos catorce kilómetros al norte de Zumbahua y a más de 3.000 metros de altura, visité también el cráter de otro volcán: el Quilotoa, en cuyo seno una laguna de un azul traslúcido muestra un paisaje de ensueño. Los lugareños han creado su propia leyenda: dicen que no tiene fondo. Los geólogos, por el contrario, han hecho añicos la imaginación y han demostrado que su profundidad es de 250 metros.

Las primaveras de 2015 y 2016 las viví en Quito con salidas aéreas a Lima. En el Centro Internacional de Estudios Superiores de Comunicación para América Latina (CIESPAL), realicé dos estancias académicas. Dicté algunas conferencias, organicé un congreso sobre periodismo narrativo y transmedia, ofrecí varios talleres sobre nuevas narrativas y tecnologías emergentes y coordiné el libro titulado Periodismo narrativo en América Latina, que vio la luz en 2017 y que la editorial Comunicación Social volvió a publicar en 2018. No todo fue trabajo, naturalmente. Cuando viajo, me gusta recorrer las calles de las ciudades, entrar en restaurantes y bares, otear paisajes, confundirme con sus habitantes. En aquellos meses recopilé material sobre el Cotopaxi, entrevisté a vulcanólogos, a políticos, a indígenas que viven en sus laderas. El mundo de los volcanes comenzó a obsesionarme. Pensé escribir un libro sobre el tema. Ahí sigue. Cualquier día le doy forma.

Brasil, adonde viajé en tres ocasiones, también me inspiró para escribir una breve novela: Escrito en Brasil, publicada en 2009. En el primer y tercer viajes me acompañó Francisco Sierra. En el primero recalamos en Brasilia y Natal. Brasilia me abrazó y me abrasó. Era una ciudad de avenidas amplísimas. Declarada capital de Brasil en 1960, es una ciudad planificada que cuenta con emblemáticos edificios blancos de arquitectura moderna, concebidos principalmente por Oscar Niemeyer. Está diseñada como un avión y podría decirse que su fuselaje lo conforma el Eje Monumental, que consta de dos avenidas que flanquean un enorme parque. La cabina la compondría la plaza de los Tres Poderes, denominada así por las tres ramas del gobierno que la rodean. Delante de la cabina estaba ubicado nuestro hotel, donde la camarera, Roberta, la última noche, nos advirtió que habíamos acabado con toda la cachaça de aquel establecimiento. Sorprendente y un honor para nosotros ser los primeros en algo.
Un congreso nos llevó a otro. Esta vez a Natal. Allí conocimos el auténtico Brasil, el Brasil del mestizaje, del encuentro entre culturas y razas, la tierra donde la danza y la música viven en la epidermis de sus ciudadanos. Donde la alegría es tan fácil de identificar como la desigualdad social. Ponta Negra es la playa de Natal, capital de Rio Grande do Norte. No solo es una playa, sino una zona turística que atraviesa de punta a punta toda la zona. Las guías turísticas cuentan que Natal es la ciudad del sol, porque al año tiene alrededor de trescientos días de sol con una temperatura media de $28^{\circ}$. Ponta Negra es además el segundo lugar del mundo con el aire más puro del planeta después de la Antártida. La zona es segura y por las noches puedes caminar por sus calles y beber caipirinha en locales abiertos al exterior con música ensordecedora donde las mujeres gritan y bailan las danzas locales con una destreza que no es de academia.

Dicen que Ponta Negra es la mejor playa de la zona, pero yo amo por razones personales Pipa, un lugar tranquilo donde los delfines son un reclamo turístico, o aquellas otras playas vírgenes como Genipabú o Maracajú, a las que uno se acerca en buggy sorteando dunas, tierras también vírgenes y cruzando el río Potengi. A Francisco Sierra le impactó aquel viaje insólito. Y eso que a él no le entusiasma el deporte de riesgo. Nos sentamos a una mesa en el lago Pitangui. Las mesas curiosamente estaban dentro del lago, en la orilla, y el agua nos cubría hasta las rodillas mientras multitud de peces pequeños revoloteaban en torno a nosotros desparasitándonos de la cultura occidental. Igual eran espías encubiertos. Es broma.

El tercer viaje a Brasil nos llevó a Bauru, ciudad universitaria, para impartir unos cursos de postgrado. El municipio tiene una gran actividad universitaria. Allí se encuentran: Campus de la Universidad de São Paulo, donde funcionan las Facultades de Odontología de Bauru (una de las mejores facultades de Odontología de Brasil y la tercera mejor del mundo); Facultades Integradas de Bauru (FIB); Instituição Toledo de Ensino (ITE); Universidade do Sagrado Coração (USC); Universidad Estatal Paulista (UNESP) y Universidade Paulista (UNIP). Antes, nos purificamos en São Paulo durante unos días, antes de que el coche oficial nos recogiera para ejercer como docentes, que es a lo que íbamos.

São Paulo tiene la mayor flota de helicópteros del mundo, 30.000 taxis, 7.000 líneas de ómnibus urbanos, 38.000 bares y restaurantes; el plato oficial es la pizza; y allí viven alrededor de 30.000 millonarios. Paseando por la avenida Paulista, me detengo en un mercadillo de cerámicas y maderas talladas, de joyas artesanas y libros raros. En uno de estos puestos ambulantes encuentro la primera edición de Residencia en la tierra, de Pablo Neruda. Solo cuesta ochocien- 
tos reales. Pero no tengo dinero suficiente. Después me he arrepentido hasta la saciedad de no haberlo adquirido. Ya se sabe que uno solo es feliz con aquello que ama. Y la vida no siempre da una segunda oportunidad.

Varias veces fui a México. Al menos dos, acompañado por mi amigo Samuel González, último cónsul de aquel país en Andalucía. Con él y los amigos recorrí la ciudad de México, la ruta de los volcanes, la península de Yucatán. Tomé burritos y enchiladas, quesadillas, degusté, no sin reparos, los gusanos de maguey y los huevos de hormiga. "Si salta, corre o vuela, a la cazuela», dice un viejo proverbio gastronómico que se aplica a los escamoles, esos huevos de hormiga que se equiparan al caviar por su precio y exquisito sabor.

Pero la ciudad que más me impresionó de México fue Juárez, fronteriza con Estados Unidos, tierra de indios apaches, atravesada por el río Bravo, adonde fui para impartir un curso de doctorado sobre periodismo y literatura. Cruzo la frontera hasta El Paso, ciudad legendaria de conquistas a grupa de caballo por el desértico Oeste americano. Juárez es ciudad apacible y emprendedora, aunque buena parte de su economía está condicionada a las maquiladoras. Es, con toda seguridad también, la ciudad más fea del mundo. A sus vecinos les preocupaba su imagen de cadena incontenible de crímenes atroces. En los vertederos ubicados a las afueras de la ciudad, no dejaban de aparecer cadáveres de mujeres. Veo cinco o seis cruces de color rosado donde aparecieron algunos cuerpos. Mientras estoy en la ciudad, leo la novela póstuma de Roberto Bolaño 2666, en la que narra los crímenes de estas mujeres salvajemente asesinadas. En realidad, el libro es un homenaje al periodista Sergio González, quien murió hace unos años y fue pionero en la investigación de estas muertes. Dejó testimonio de sus investigaciones en el libro Huesos en el desierto. González Rodríguez fue, sin duda, un periodista comprometido y excepcional. Excepcional en sus indagaciones y en su prosa perfectamente pulida.

En Ciudad Juárez bebo tequila, pero también sotol reposado. Sotol mesteño, que es del lugar. El sotol es un tipo de mezcal extraído de una agavácea que solo crece en el desierto chihuahuense, al igual que el mesteño, caballo salvaje que nace y muere libre en las grandes llanuras del norte. Pero en Juárez se bebe también whisky elaborado en la ciudad desde 1909 por D. M. Distillery Co., S. A. En los años de la ley seca, esta destilería vendió miles de cajas de botellas de Juárez American whiskey al país vecino. Dicen que por allí apareció alguna vez Al Capone. Se supone que para comprobar la calidad de la mercancía. La calidad, en cualquier caso, es superior. Sin duda, es de los mejores whiskies que he degustado.
Si rememoro América, no puedo olvidar Chile, un país que inevitablemente une su nombre al de Pablo Neruda. Impartí allí un seminario sobre periodismo en Concepción. Después volví a Santiago, una ciudad tantas veces traicionada por militares gozosos del poder arrebatado al pueblo. La Casa de la Moneda, el estadio de fútbol me retrotraen a los años de la represión del general Pinochet. Visité la tumba de Salvador Allende, recordé el perfil comprometido y bueno de Víctor Jara. Me acerqué, con Claudia Mellado, inevitablemente a Isla Negra. Conocía sus rincones de haberlos leído, el océano bravo rompiendo sus olas contra las rocas, las tumbas de Pablo y de Matilde, su colección de conchas, su colección de botellas, sus mascarones, el cuerno de narval, su mundo propio representado en objetos recogidos por medio mundo. Una casa que nunca dejaba de crecer frente al océano Pacífico que le vio morir del dolor propio y ajeno. Antes o después, estuvimos una semana en Isla de Pascua, donde la única carretera era el aeropuerto. Denominémoslo así. Toros y caballos salvajes y libres habitaban la isla. El océano manso del color de un carbón metálico. Isla de Pascua es el rincón habitado más alejado de cualquier parte del planeta. Allí ves el cielo y tocas la soledad.

Pero fue Cuba el país que primero visité de América Latina. La Habana es, sin duda, una de las ciudades más bellas del mundo. Andar La Habana Vieja, entrar en la Bodeguita del Medio, tasca tradicional, con las paredes escritas y fotografías enmarcadas de famosos, donde se sirven mojitos. ¿Y "del medio» por qué? Porque todas las tabernas están ubicadas en las esquinas, al final de la calle. Menos esta. Entrar en Floridita, más conocido como El Floridita, bar y restaurante desde 1817. Se hizo mundialmente famoso gracias al escritor y periodista Ernest Hemingway, quien acostumbraba visitarlo con regularidad. De hecho, ahí sigue en forma de estatura de bronce apoyado en la barra. Cuna del daiquiri, he pasado tardes enteras con el profesor Francisco Estévez y Claudia Mellado bebiendo al lado del inmortal premio Nobel. En su nombre, siempre pedía un daiquiri papá Hemingway. ¿Por qué se denominaba así? Porque contenía doble ración de ron. Visité su casa a las afueras de la ciudad. Escribía de pie. No lo entiendo. ¿Cuántas veces leí El viejo y el mar? Ya no recuerdo. Dejé a unos cuantos amigos allá.

¿Cuándo cruzaré de nuevo el océano Atlántico para ir a América Latina? En realidad, no sé si he regresado de aquel continente desde entonces. Si no fuera así, la próxima vez haré escala en las islas Azores. Tengo pendiente tomar allá el mejor gintónic del mundo a la salud de Antonio Tabucchi, uno de mis escritores de cabecera. Mientras espero, tomo otro gintónic y releo, una vez más, Dama de Porto Pim. Hay esperas que, aunque se prolonguen, valen la pena. 